Vol. 18 No. 2, 2020
ISSN (online): 2746-4652
doi: https://doi.org/10.33369/jwacana.v18i2.14870

\title{
KAJIAN PERWATAKAN TOKOH-TOKOH NOVEL” LAUT BERCERITA” KARYA LEILA S. CHUDORI
}

\author{
${ }^{1}$ Pebria Renita, ${ }^{2}$ Amrizal, ${ }^{3}$ Yayah Chanafiah \\ ${ }^{1,2,3}$ Universitas Bengkulu
}

Korespondensi: pebriarenita@gmail.com

\begin{abstract}
Abstrak
Tujuan penelitian ini adalah untuk mengetahui perwatakan tokoh-tokoh dalam Novel Laut Bercerita Karya Leila S. Chudori. Penelitian ini menggunakan metode deskriptif kualitatif. Teknik analisis data (a) Peneliti menganalisis unsur-unsur novel Laut Bercerita yang mendukung perwatakan tokoh-tokoh novel Laut Bercerita (b) Peneliti menganalisis perwatakan tokoh-tokoh novel Laut Bercerita karya Laila S.Chudori. Hasil penelitian menunjukkan bahwa data yang memuat unsur-unsur novel Laut Bercerita. Unsur-Unsur tersebut adalah tema, alur, dan latar. Tema dalam novel Laut Bercerita karya Laila S.Chudori adalah legitimasi dan perjuangan melawan masa Orde Baru.Alur dari Novel Laut Bercerita adalah alur maju yang mendeskripsikan pengenalan tokoh, pokok persoalan dan klimaks cerita. Latar cerita novel Laut Bercerita banyak terjadi di Desa, Kampus dan di Sekretariat. Pokok pembahasan dalam penelitian ini adalah Biru Laut dalam novel Laut Bercerita digambarkan pengarang sebagai tokoh yang memiliki watak bersemangat, tidak mudah terpengaruh/teguh pendirian, pendiam, pemalu, penyayang, pemberani, pantang menyerah, dan tenang. Ditinjau dari segi psikologi sastra Sigmund Freud tokoh Biru Laut memiliki id berupa mudah khawatir atau cemas, pendiam. Ego pemalu, penyayang. Super Ego pemberani, tenang, bersemangat dan pantang menyerah
\end{abstract}

Kata Kunci: Perwatakan tokoh, Laut Bercerita.

\begin{abstract}
The purpose of this research is to know the characters in the Novel Laut Bercerita by Leila S.udori. This research used descriptive qualitative method. Data analysis techniques (a) The elements of the novel Laut Bercerita that supports the characterizing of novel characters in Laut Bercerita by Leila (b) The researcher analyzes the disposition of Laut Bercerita novel characters by Laila S.Chudori. The results showed that the data presented was data that contained elements of the novel Laut Bercerita. The elements are meeting, plot, and setting. The theme in the novel Laut bercerita is legitimacy and stroggle against the new order. The plot of this novel is the flow forward, which describes the introduction of characters. Subject matter and stori climax. The setting of the story in the novel Laut Bercerita occurs in village, campuses and the secretariat. The subject of this research is Blue Sea in the novel Laut Bercerita described by the author as a character who has a passionate character, not easily influenced / firm, quiet, shy, merciful, brave, unyielding, and calm. Whereas in terms of literary psychology Sigmeund Freud, the figure of the Blue Sea has the id of being easily worried or anxious, quiet. The ego is shy, merciful. Super Ego brave, calm, vibrant and never gives up.
\end{abstract}

Keywords: character disposition, sea storytelling 


\section{PENDAHULUAN}

Karya sastra terdiri dari berbagai jenis, salah satunya adalah novel. Burhan Nurgiyantoro (2010:4) menyatakan bahwa novel sebagai suatu karya fiksi yang menawarkan sebuah dunia, yaitu dunia yang berisi suatu model yang diidealkan, dunia imajinatif, yang dibangun melalui berbagai unsur intrinsiknya, seperti peristiwa, plot, tokoh dan penokohan, latar sudut pandang yang bersifat imajinatif. Oleh karena itu, novel merupakan salah satu wadah bagi pengarang dalam menuangkan segala hal yang ada dalam pikirannya.

Novel merupakan jenis karya sastra yang ditulis dalam bentuk naratif yang mengandung konflik tertentu dalam kisah kehidupan tokoh-tokoh dalam ceritanya. Biasanya novel kerap disebut sebagai suatu karya yang hanya menceritakan bagian kehidupan seseorang. Hal ini didukung oleh pendapat Sumardjo (1984:65) yaitu novel sering diartikan sebagai hanya bercerita tentang bagian kehidupan seseorang saja, seperti masa menjelang perkawinan, setelah mengalami percintaan atau bagian kehidupan waktu seseorang tokoh mengalami krisis dalam jiwanya dan sebagainya.

Novel Laut Bercerita merupakan novel kedua Leila S. Chudori yang telah berhasil menyentuh hati pembaca setelah novel Pulang. Leila S. Chudori merupakan penulis Indonesia yang menghasilkan berbagai macam karya seperti cerita pendek, skenario drama televisi, dan novel. Leila itu sendiri lahir di Jakarta 12 Desember 1962 dan menempuh pendidikan di Trent University, Kanada. Dalam novelnya yang berjudul Laut Bercerita terdapat beberapa tokoh yang dimunculkan dan memiliki perwatakan yang berbeda-beda. Tokoh-tokoh yang ada yaitu: Biru Laut, Kinan, Gusti, Asmara, Naratama dan masih banyak tokoh lainya. Pengarang menjadikan tokoh Biru Laut sebagai tokoh utama. Biru Laut adalah seorang mahasiswa aktivis yang menempuh pendidikan sastra Inggris di Yogyakarta yang memiliki semangat tinggi membela kaum kecil yang tertindas oleh pemerintah, maka dari itu Laut dan teman-temannya membuat organisasi yang bernama Winatra.

Biru Laut merupakan anak yang berbakti terhadap kedua orang tuanya. Selain itu, Biru Laut juga memiliki sifat penyayang di mana terlihat bahwa dia begitu memperhatikan adiknya pada saat ada seorang teman laki-laki Asmara yang datang ke rumah. Biru Laut memperhatikan gerak gerik teman adiknya itu, karena Biru Laut takut laki-laki berbadan kurus dan berambut gimbal tersebut berniat buruk kepada adiknya. Tokoh-tokoh yang terdapat di dalam novel Laut Bercerita karyaLeila S. Chudori memiliki sifat yang menekankan pada perjuangan, sehingga tergambar sifat setia kawan dan juga terdapat sifat yang tercelah yaitu penghianatan seperti yang di gambarkan pada tokoh Gusti. Gusti adalah tokoh yang kaya, pendiam, dan seolah memberikan semua kebutuhan yang diperlukan dalam organisasi, namun pada akhirnya ialah yang menjadi penghianat sesungguhnya.

Berbanding terbalik dengan karakter Tama yang dicurigai sebagai dalang penghianatan karena sikap Tama yang sering menggebu-gebu, menusuk lawan bicara pada saat berdiskusi itu lebih bekorban membela ketidakadilan pemerintahan. Selain itu, ada tokoh lainnya yang berpengaruh dalam menghidupkan suasana dalam novel dengan watak dan cerita tokoh masingmasing.

Dalam penelitian ini penulis lebih terfokus pada perwatakan tokoh, untuk membantu dalam menganalisis perwatakan tokoh penulis tuangkan dengan rumusan masalah bagaimana unsur-unsur novel Laut bercerita karya Leila S.Chudori yang mendukung perwatakan tokoh dan bagaimana perwatakan tokoh novel Laut Bercerita Karya Leila S.Chudori. Maka dari itu, penelitian ini bertujuan untuk mendeskripsikan unsu-unsur yang mendukung analisis perwatakan tokoh di dalam novel Laut Bercerita karya Leila S.Chudori dan mengetahui karakter tokoh novel Laut Bercerita karya Leila S.Chudori.

Hardy dalam Sukada (1987: 63) mengungkapkan bahwa perwatakan merupakan imaji penulis dalam membentuk personalitas tertentu dalam ceritanya sehingga menimbulkan kepercayaan terhadap cerita bahwa tokoh-tokoh tersebut berkelakuan seperti dalam kehidupan 
yang sebenarnya. Pendapat ini sejalan dengan pendapat William Flint dan Addison Hibbard (1960:79) yang menyebut perwatakan sebagai gambaran kreatif tentang tokoh-tokoh bayangan yang dapat dipercaya demikian rupa, karena mereka hadir di depan pembaca seperti sesungguhnya.

Pengarang menjadikan manusia hidup yang hidup di alam nyata sebagai model penciptaanya. Oleh karena itu, dalam sastra ilmu psikologi digunakan sebagai salah satu pendekatan untuk meneladani atau mengkaji tokoh-tokohnya. Maka, dalam menganalisis tokoh dalam karya sastra dan perwatakannya seorang pengkaji sastra harus berdasarkan pada teori dan hukum-hukum psikologi yang menjelaskan periilaku dan karakter manusia. Sigmund Freud adalah psikolog pertama yang menyelidiki aspek ketidaksadaran dalam jiwa manusia. Freud semakin terfokus perhatiannya pada masalah psikologi tokoh. Dia juga dapat menganalogikan tokoh-tokoh dalam karya sastra. Teori freud dimanfaatkan untuk menggungkapkan berbagai gejala psikologis di balik gejala bahasa (Endras-wara, 2008:4).

Berdasarkan sejumlah pemaparan penulis di atas tentang Novel Laut Bercerita Karya Leila S. Chudori yang mengisahkan tokoh Biru laut yang sangat mendominasi jalan cerita dalam novel dan teman-temanya dalam memerangi kekejaman rezim orde baru dan sejumlah peristiwa-peristiwa yang terjadi dalam novel yang penulis anggap menarik untuk di teliti secara mendalam maka penulis terinspirasi untuk mengangkat Novel Laut Bercerita sebagai bahan penelitian dengan judul “Käjan Perwatakan Tokoh-tokoh Novel Laut Bercerita karya Leila S. Chudori”.

\section{METODE}

Penelitian ini menggunakan metode deskriptif kualitatif. Pendekatan yang digunakan dalam penelitian ini adalah pendekatan psikologi sastra. Data penelitian ini merupakan data verbal yang berupa kata-kata, kalimat atau paragraph yang berupa narasi atau dialog, kalimat yang berisi seputar perwatakan tokoh-tokoh. Sumber data yang digunakan adalah novel Laut bercerita karya Leila S.Chudori, novel cetakan ketiga, Januari 2018 terbitan Kepustakaan Populer Gramedia, Jakarta dengan tebal buku 379 halaman.

Adapun langkah-langkah analisis data penelitian sebagai berikut:

1. Menandai setiap narasi dan dialog yang mengandung perwatakan tokoh-tokoh novel Laut Bercerita karya Leila S.Chudori.

2. Mencatat setiap narasi dan dialog yang mengandung perwatakan tokoh-tokoh novel Laut Bercerita karya Leila S.Chudori.

3. Menganalisis perwatakan tokoh-tokoh Laut Bercerita Karya Leila S.Chudori

4. Menarik kesimpulan

\section{HASIL DAN PEMBAHASAN}

Berdasarakan hasil analisis Unsur Instrinstik sebagai unsur pembangun perwatakan tokoh utama, Watak tokoh-tokoh dalam novel Laut Bercerita karya Leila S.Chudori, Watak tokoh Biru Laut ditinjau dari psikologi sastra Sigmeund Freud

Berikut penulis paparkan secara lengkap:

a. Unsur Instrinstik sebagai unsur pembangun perwatakan tokoh utama

penulis mengkaji perwatakan tokoh Biru Laut secara mendalam dengan mengkaji unsurunsur yang berkaitan dengan pembentukan Watak Tokoh Biru Laut. Berikut Penjelasannya:

\section{Tema}

Unsur instrinstik pertama yang memiliki keterkaitan dengan watak tokoh Biru Laut adalah tema. Novel Laut Bercerita mengangkat tema yang berisi perjuangan sekelompok orang yang terdiri atas mahasiswa dan masyarakat sipil yang memperjuangkan keadilan dengan 
cara melakukan aksi dan diskusi untuk lepas dari orde baru yang memimpin lebih dari sepuluh tahun dengan sewenang wenang.

\section{Alur}

Dalam menciptakan karya fiksi, seorang penulis harus menciptakan alur

Yogyakarta seperti di Kecamatan Seyegan. Seyegan merupakan lokasi sekretariat Winatra untuk melakukan kegiatan adminstratif untuk diskusi dan rencana gerakan diawal kisah terdapat deskripsi latar tempat terlihat dari kutipan berikut:

Aku baru menyadari, bunyi ketukan halus itu datang dari jari-jari Sunu pada pintu calon rumah kami di Seyegan, di sebuah pojok terpencil di Yogyakarta (Chudori, 2018:10).

Gambaran latar tempat sebuah daerah di sudut kota Yogyakarta, dideskripsikan sebagai rumah hantu yang kotor dan bau pesing karena sudah lama tak ditunggu, seperti yang terlihat dalam kutipan berikut:

Apa julukan rumah ini, Dan? Kinan bertanya menyembunyikan senyumnya. "Rumah Hantu”. Mereka bilang setiap malam jum'at ada hantu yang tidur-tiduran di sini, Alex menyela sambil terus memotret dapur atau mungkin lebih tepat untuk menamkannya bekas dapur.Tentu saja kami tak peduli dengan hantu yang tidur-tiduran pada malam jum'at.Kami juga tak peduli betapa kotornya dan berantakannya rumah ini (Chudori, 2018:14).

Kutipan di atas menggambarkan sengeri apapun tempat sekretariat Winatra, Laut dan teman-temannya tidak memperdulikan dengan adanya hantu tersebut, mereka masih tetap bertahan di rumah hantu demi keamanan mereka untuk berdiskusi dan melakukan pergerakan. Latar tempat lainnya yang dideskripsikan oleh pengarang yaitu di Jakarta, Jakarta merupakan ibu Kota yang terkenal dengan macet karena padatnya penduduk.seperti tampak pada kutipan berikut:

"Malam itu terasa semakin malam. Tiba-tiba saja aku merasa seluruh isi Jakarta tak bergerak.Aku ingat betul begitu tiba di rumah susun, aku merasa agak gerah, maka kuputuskan untuk langsung mandi. Begitu keluar dari kamar mandi, aku baru menyadari bahwa lampu padam, ini memang bukan sesuatu yang ganjil di rumah susun yang sering mengalami pemadaman listrik" (Chudori, 20018:51).

Laut merasa hari semakin hening, tinggal di rumah susun yang sempit itu membuatnya gerah dan dia pun memutuskan untuk mandi. Selain itu rumah susun juga digambarkan sebagai rumah yang sering mengalami pemadaman lampu.

Latar berikutnya di rumah Romo, Rumah romo digambarkan pengarang sebagai rumah terpencil yang begitu tenang karena jauh dari perkotaan. Berikut kutipannya:

Rumah Romo Mulyana terpencil di balik kerimbunan bunga alamanda yang dinaungi pohon kamboja kuning.Aku merasa tenang karena udara sejuk halaman rumah ini memberikan rasa aman. Apalagi letaknya terasa jauh dari pusat kota Bogor. Ketika Daniel melangkah menuju rumah bersama Gusti yang mengetuk pintu, Julius menahan lenganku (Chudori, 2018:208)

Selanjutnya berlatar di Istana Negara.

"Pada kamis keempat, di awal tahun 2007 itu, di bawah matahari senja, di hadapan Istana Negara, kami berdiri dengan baju hitam dinaungi ratusan payung hitam. Kami tak beteriak atau melonjak, melainkan bersuara dalam diam. Keringat matahari sore membuat baju kami kuyup, tapi itu malah membuat suasana semakin guyub. Bram dan Aswin memberi pengarahan pada awal, sementara Daniel memegang toa sesekali memberi orasi pendek meski satu dua polisi gelisah karena para penggemudi mobil yang berlalu jadi berjalan perlahan karena kepingin nonton. Naratama dan bersama beberapa wartawan asing dan lokal bergerombol memotret, merekam, dan mewawancarai para orang tua, Bram dan Aswin. Alex mencoba merekam foto para ibu, kakak, adik, keponakan, istri, kekasih yang 
memegang 13 foto-foto mereka yang belum kembali, di antaranya Sunu, Julius, Gala, Widi, Kinan, Narendra (Chudori, 2018:362)."

Kutipan di atas menggambarkan bahwa mereka yang kehilangan anak-anaknya akibat penculikan mencoba untuk meminta keadilan di depan Istana Negara untuk menindaklanjuti kasus ini, mereka para orang tua, adik, istri dan kekasih ingin mengetahui jasad anak-anaknya dimana jikalau benar sudah meninggal. Namun apalah daya orang yang berkuasa hanya bungkam.

b. Watak tokoh-tokoh dalam novel Laut Bercerita karya Leila S.Chudori

Berikut penulis paparkan watak-watak tokoh tokoh dalam novel Laut Bercerita karya Leila S.Chudori:

\begin{tabular}{|l|l|l|}
\hline No & Tokoh & Watak/Karakter \\
\hline 1. & Biru Laut & $\begin{array}{l}\text { Enerjik/bersemangat, teguh, pendiam, pemalu, tenang, } \\
\text { pemberani, penyayang. }\end{array}$ \\
\hline 2. & Kasih Kinanti & Tenang, lembut, jenius dan realistis. \\
\hline 3. & Naratama & Suka mencela dan mencemooh. \\
\hline 4. & Gusti & Dingin dan dermawan. \\
\hline 5. & Alex & Baik dan sopan. \\
\hline 6. & Daniel & Manja dan cerewet. \\
\hline 7. & Sunu & Bijaksana, pendiam dan suka membantu. \\
\hline 8. & Bapak & Penyayang, lembut dan pemberani. \\
\hline 9. & Asmara & Penyayang, kritis dan realistis. \\
\hline 10 & Gala Pranaya & Pemberani, tidak mudah putus asa, dan bijaksana. \\
\hline 11 & Ibu & Lembut dan penyayang. \\
\hline 12 & Bram & Pemberani dan memiliki semangat yang tinggi. \\
\hline 13 & $\begin{array}{l}\text { Empat Sekelompok } \\
\text { Penjahat }\end{array}$ & Kejam dan licik. \\
\hline
\end{tabular}

\section{c. Watak tokoh Biru Laut ditinjau dari psikologi sastra SigmeundFreud}

Adapun watak Laut Biru sebagai tokoh utama dalam novel adalah bersemangat, cuek, pendiam, pemalu, pemberani, penyayang, dan tenang. Berikut penulis paparkan dalam struktur kepribadian manusia:

a. Id

\section{Pencemas}

Pencemas merupakan khawatir berlebihan yang dimiliki seseorang, yang kerap kali mengkhawatirkan sesuatu hal yang belum tentu akan terjadi di masa yang akan datang. Seperti halnya yang dialami tokoh Biru Laut dalam novel. Berikut kutipankutipan yang memperlihatkan sifat pencemas yang dimiliki oleh tokoh Biru Laut: Kutipan 1

"Tiba-tiba saja ruang makan menjadi sepi dan tak nyaman. Aku membayangkan semua kawan-kawanku mana mungkin mereka intel? Naratama? Itu lagi. Dia memang menyebalkan, tapi Intel (Chudori, 2018:76).

Dari kutipan di atas, dapat dilihat bahwa terdapat bentuk watak cemas atau khawatir yang diperlihatkan oleh tokoh Laut. Laut merasakan kekhawatiran karena ia membayangkan jika salah satu di antara temanya ada yang menjadi mata-mata dalam aksi yang mereka lalukan. Laut merasa curiga dengan salah satu temanya, sehingga perasaan curiga inilah yang mneyebabkan rasa cemas pada diri Laut. Terlebih Laut juga telah diberitahu oleh Ayahnya, jika semua orang 
bisa jadi Intel, kita tidak pernah tau siapa lawan dan siapa kawan maka dari itu laut merasa curiga dan khawatir jika salah satu temanya adalah Intel.

Kutipan 2

"Aku tidak menjawab, karena sebetulnya mulai bulan depan memang secara resmi kutinggalkan. Asmara danaku berputar-putar debat soal geografi dan lokasi, tapisesungguhnya dia sedang menegur kegiatanku yang menyerempet bahaya” (Chudori, 2018:87).

Laut merasa khawatir karena dalam perbincangan dengan adiknya ia beranggapan bahwa adiknya akan membocorkan rahasia kegiatan dalam aktivis yang diikutinya kepada kedua orangtuanya. Laut khawatir karena jika adiknya membicarakan kegiatanya dalam aktivis maka bisa saja sesuatu hal yang buruk yang akan terjadi. Jika kedua orangtuanya megetahui kegiatanya sudah pasti Laut akan dipindahkan dan tidak diizinkan megikuti kegiatan aktivis yang dapat membahayakan dirinya termasuk juga keluarganya.

Kutipan 3

"Aku ingat betapa aku ingin sekali meneleponya untuk mengucapkan selamat ulang tahun dan menjanjikan buku apa saja yang disukainya, tapi mustahil. Di masa buron seperti ini segala medium komunikasi dengan keluarga diminimalisir. Karena itu akau hanya mengucapkanselamat ulang tahun dalam hati” (Chudori, 2017:51).

Laut merasa takut karena dirinya sedang menghadapi suatu masalah dan kejadian karena terlibat dalam sebuah aktivis dan menjadi buron. Rasa takut muncul karena dirinya berada dalam kekhawatiran, keragu-raguan dan rasa gelisah yang sangat kuat sehingga apa yang diyakini mungkin akan terjadi.

Kutipan 4

"Suara ketukan yang terdengar keras dan tak sabar. Aku tak langsung membukanya. Jantungku mulai berdebar-debar. Perlahan aku melangkah ke dalam kamar dan melongok ke arah luar jendela. Karenakamar kami berada di lantai rumah susun, aku bisamengintip dari bawah. Kulihat ada beberapa lelaki berbadan kekar mengenakan sebo penutup wajah wol" (Chudori, 2017:52).

Dari kutipan dapat dilihat bahwa Laut merasa takut karena ada beberapa orang menggedor pintu dan memaksa masuk. Ia takut untuk membuka pintu karena ia beranggapan mereka adalah orang-orang yang menculik sahabatnya Sunu. Ia takut jika orang-orang itu juga akan menyekapnya sama seperti sahabatnya Sunu. Rasa ketakutan tersebut membuat Laut menjadi resah karena sudah pasti mereka akan menginterogasi dan menculiknya.

\section{Pendiam}

Biru Laut memiliki watak pendiam sejatinya. Ia hanya lantang dan panjang lebar berbicara hanya saat mengkritisi pemerintahan, jika dalam kehidupan sehari-hari ia lebih banyak diamnya. Berikut kutipan pendukung yang memperlihatkan watak tokoh Biru Laut yang pendiam:

"Mata Kinan bersinar-sinar mendengar ceritaku dan mengomentari bahwa ternyata aku bisa juga berbicara agak panjang” (Chudori, 2018:22).

Dari kutipan terlihat bahwa Laut merupakan sosok pendiam yang tak banyak bicara.Ia hanya banyak bicara melalui ide ide kreatifnya dalam melawan pemerintah.

\section{b. Ego}

1. Pemalu

Orang pendiam kerap kali memiliki sifat pemalu, meskipun tak semuanya begitu. Pemalu kerap kali dikaitkan sebagai penyebab watak diam seseorang. Biru Laut memiliki watak pemalu, seperti halnya terlihat pada kutipan berikut ini:

"Aku sangat tergoda untuk kembali kesana, dan berdiskusi tentang kehidupan sang Rusa Merah, tetapi aku sangat tahu diri, aku bukan Naratama yang fasih atau Gusti yang senyumnya mengikat hati wanita” (Chudori, 2018:38). 
Dari kutipan di atas bisa terlihat watak tokoh Laut yang pemalu dan rada minder karena ia merasa tak memiliki gaya bicara yang fasih dan senyum yang manis seperti teman temannya.

\section{Penyayang}

Penyayang dan lemah lembut merupakan suatu watak yang sudah menjadi satu kesatuan.Hal tersebut terlihat pembuktianya pada tokoh Biru Laut yang memiliki sifat penyayang pada orang terdekatnya dan sering kali menunjukkan sifatnya yang lemah lembut. Terlihat dari kutipan berikut ini:

"Aku menghampiri ibuku yang sedang mengelap tangganya celemek dan aku mencium punggung tangganya yang masih bau kunyit dan bawang putih yang membuat semakin rindu sekaligus terharu (Chudori, 2018:63)

Dari kutipan di atas terlihat bagaimana watak seorang tokoh Laut yang memiliki watak penyayang terlebih lebih pada ibu dan adiknya, hal tersebut terbukti dari perlakuanya pada keduanya.

\section{c. Super Ego}

\section{Pemberani}

Biru Laut memiliki sifat pemberani, terlihat dari kutipan berikut ini:

"Peristiwa ini sama sekali tak mengurangi militansiku, atau kawan-kawan yang lain, aku melirik Julius yang sedari tadi tak bersuara" (Chudori, 2018:182).

Dari kutipan terlihat bahwa Laut merupakan seorang pemuda pemberani yang tak gentar,meskipun di dalam kondisi yang menakutkan sekalipun.

\section{Bersemangat}

Biru Laut memiliki watak positif yang selalu bersemangat, terlihat dari kutipan berikut ini:

"Gerakan mahasiswa ginatra sudah dideklarasikan secara serentak di beberapa Kota. Kaki rasanya gatal jika kami hanya berdiskusi sepanjang abad tanpa melakukan tindakan apapun” (Chudori, 2018: 12).

Kutipan di atas memperlihatkan watak Biru Laut yang begitu bersemangat dalam melaksanakan semua kegiatan.

\section{Pantang Menyerah}

Biru Laut digambarkan sebagai tokoh yang pantang menyerah dalam segala hal. Terutama dalam mengkritisi pemerintah pada masa orde baru. Disegala tekanan dan hambatan yang menghadang ia tetap tak pernah menyerah dan putus asa. Berikut kutipanya:

"Tapi aku tahu satu hal; kita harus mengguncang mereka. Kita harus mengguncang masyarakat yang pasif, malas, dan putus asa agar mereka mau ikut memperbaiki negeri yang sungguh korup dan beranatakan ini, yang sangat tidak menghargai kemanusiaan ini, Laut" (Chudori, 2018:182).

Dari kutipan di atas terlihat sifat pantang menyerah Biru Laut dalam memotivasi masyarakat agar tidak diam saja dalam melawan negeri yang di anggap korup dan tidak memihak pada rakyat.

\section{Tenang}

Tenang adalah watak yang dimiliki oleh Biru Laut di tengah situasi yang genting dan amat menyiksa. Hal tersebut dapat dibuktikan dari kutipan berikut ini:

"Alex terdengar menggeram-geram, sedangkan aku masih mencoba berdamai dengan setumpuk darah kering pada bibir, wajah bengkak, dan tulang hidung yang patah yang membuatku susah bernafas" (Chudori, 2018:93)

Dari sikap tokoh Biru Laut di atas terlihat bagaimana watak Biru Laut yang tenang dalam menyikapi situasi yang teramat sulit sekalipun. 


\section{PENUTUP}

\section{Kesimpulan}

Hasil penelitian ini yaitu unsur-unsur yang mendukung pembentukan watak tokoh utama novel Laut Bercerita adalah tema, alur, dan latar. Sedangkah perwatakan tokoh terdapat tokoh Biru laut memiliki watak bersemangat, tidak mudah terpengaruh/teguh pendirian, pendiam, pemalu, penyayang, pemberani, pantang menyerah, dan tenang. Kasih Kinanti memiliki watak tenang dan lembut. Naratama memiliki watak angkuh dan suka mencemooh. Gusti memiliki watak tidak setia dan kejam. Alex memiliki watak baik, tenang dan sopan. Daniel memiliki watak tidak sabaran dan kritis. Sunu memiliki watak bertanggung jawab dan baik hati. Bram digambarkan sebagai tokoh yang memiliki watak sabar dan bersemangat. Ditinjau dari segi psikologi sastra Sigmund Freud tokoh Biru Laut memiliki id berupa mudah khawatir atau cemas, pendiam. Ego: pemalu, penyayang. Super ego : pemberani, tenang dan pantang menyerah.

\section{Saran}

Bagi peneliti sastra, hendaknya pada peneliti selanjutnya dapat melakukan penelitian dengan lebih sempurna, baik yang berhubungan dengan penelitian ini, maupun yang berhubungan dengan masalah lain dalam penelitian yang berobjek novel laut bercerita. Sedangkan bagi pembaca, harapan penulis dengan adanya penelitian ini diharapkan meningkatkan apresiasi pembaca terhadap karya sastra karena penelitian yang dilakukan dengan memakai karya sastra sebagai penelitiannya sering kali dapat bermanfaat bagi pembaca.

\section{DAFTAR PUSTAKA}

Chanafiah, Yayah, \& Agustina, Emi. 2014. Buku Ajar Prosa Fiksi. Bengkulu: Universitas Bengkulu.

Chudori, S Leila. 2018. Laut Bercerita. Jakarta: Kepustakaan Populer Gramedia.

Endraswara, Suwardi. 2008. Metodologi Penelitian Sastra. Yogyakarta: Media Pressindo.

Nurgiyantoro, Burhan. 2010. Teori Pengkajian Fiksi. Yogyakarta: Gadjah Mada University Press.

Sukada, Made. 1987. Pembinaan Kritik Sastra Indonesia Masalah Sistematika Analisis Struktur Fiksi. Bandung: Angkasa.

Sumardjo, Jakob 1983. Memahami kesusastraan. Bandung: Alumni 